\section{Does $D$ put the Dilemma in CPD?}

\author{
Stephen Hancocks OBE \\ Editor-in-Chief
}

Send your comments to the

Editor-in-Chief,

British Dental Journal

64 Wimpole Street,

London,

W1G 8YS

Email bdj@bda.org
The overwhelming majority of us think it is 'a good thing'; patients inevitably think it is 'a good thing' and the profession's state appointed regulator the General Dental Council also thinks it is 'a good thing' because they made it mandatory. So, like one of the riddles from The Hobbit, what is it? Well, Continuing Professional Development (CPD) of course.

At the outset it seems so straightforward, but the difficulty with jolly good things is that while everybody can agree that they are, jolly good, they often disagree about the best way in which to achieve them. So, with CPD the apparently easy part is that everyone has to prove that they've done something which then means that they can provide better diagnosis, treatment or service to patients. Immediately, questions arise. How do you prove that you have 'done something'? Does everyone take your word for it, that is, trusts you as a professional to tell the truth, or is a third party needed in order to verify that you have performed some activity in some way? Attending a lecture perhaps, a meeting, going to a conference, reading a journal or a scientific paper, participating in a practice audit.

Even if you can solve that problem, how do you prove that you have learnt anything from it and even if you can do that how on earth can you demonstrate that you have put it into practice?

\section{WE NEED YOUR THOUGHTS}

The $B D J$ 's CPD programme, which we provide for readers in collaboration with UCL Eastman CPD and their partners Smileon, has now been running for nine years. During that time we have regularly debated and have had frequent questions about whether or not we should add a scoring system. That is to say, the user is required to get more than a certain number or percentage of questions correct before receiving a CPD certificate for the appropriate time. The argument runs that implementing such a system would make it harder for untrustworthy individuals to cheat the system by merely ticking boxes at random; thereby safeguarding the public. But is that the case or is it spurred by individuals who perceive that others could be getting away with less time and effort for the same outcome and that this riles them because they are too conscientious to similarly even consider trying to buck the system?

Conversely, it can be argued that if the GDC felt that this was necessary it would have included this requirement in its criteria for recognising verifiable CPD. Additionally, educationalists will point out that it is participating in the activity that is educational, not necessarily getting all or any of the questions correct but then going back on the answers that one got wrong and reflecting again on the material to find out why.

Whatever the pros and cons, we would like to know what you think. In the region of 4,000 readers complete the BDJ's CPD programme across the two issues of any given month from a registered total of over 16,500 users. As a user do you feel that a system which requires you to gain a certain percentage of correct answers before you can receive a CPD certificate is a good idea, enhances professionalism and reduces potential cheating? Or is this an unwanted imposition that adds little or no educational value, punishes ethical users and is not mandated? If you are not a user, are any of these the reasons why you do not participate or do you just prefer to gather your CPD in other ways? In order for us to better understand your stance on this we have a survey running which you can access via the CPD home page www.bdjeastmancpd.com before 31st July 2012. To encourage participation we are offering the chance of being entered into a draw to win an iPad. We will publish the results and will also use them in crafting a way forward with our CPD programme.

Whether or not we stay with the status quo or move to a system designed to provide more robust safeguards against possible fraudulent use, the fundamental questions and dilemmas over how to 'prove' the three elements of CPD being a 'good thing' remain; participation, educational gain and actual implementation of the lessons learned. Such a simplistic, linear chain of events is rarely the way in which change occurs in the complex situation of clinical care. Even if it did, there would be an explicit implied need for a policing system in order to ensure that it was rigorously applied. In turn, this begs the need for every professional to have another professional overseeing their work constantly; undermining the philosophy behind professionalism itself.

Perhaps instead of the D standing for dilemma we can for the meanwhile designate it as being for debate. It would be very good to open discussion on the extent to which we can and should be trusted to conduct our own CPD through learning and reflection and conversely on how much supervision we think is required to discourage and weed out those who cheat and abuse the systems. Please be in touch.

DOI: 10.1038/sj.bdj.2012.421 